\title{
Robotic Total Mesorectal Excision for Rectal Cancer: Current Evidences and Future Perspectives
}

\author{
Je-Ho Jang, Chang-Nam Kim \\ Department of Surgery, Eulji University School of Medicine, Daejeon, Korea
}

Despite the technical limitations of minimally invasive surgery, laparoscopic total mesorectal excision (LTME) for rectal cancer has short-term advantages over open surgery, but the pathological outcomes reported in randomized clinical trials are still in controversy. Minimally invasive robotic total mesorectal excision (RTME) has recently been gaining popularity as robotic surgical systems potentially provide greater benefits than LTME. Compared to LTME, RTME is associated with lower conversion rates and similar or better genitourinary functions, but its long-term oncological outcomes have not been established. Although the operating time of RTME is longer than that of LTME, RTME has a shorter learning curve, is more convenient for surgeons, and is better for sphincter-preserving operations than LTME. The robotic surgical system is a good technical tool for minimally invasive surgery for rectal cancer, especially in male patients with narrow deep pelvises. Robotic systems and robotic surgical techniques are still improving, and the contribution of RTME to the treatment of rectal cancer will continue to increase in the future.

Keywords: Rectal neoplasms; Total mesorectal excision; Robotic surgical procedures

\section{INTRODUCTION}

Treatment of rectal cancer has improved with multimodal treatments such as preoperative neoadjuvant chemoradiotherapy, radical surgery using total mesorectal excision (TME), and adjuvant chemotherapy. Radical resection is a key step in the standard treatment of rectal cancer and is considered important for favorable oncological outcomes. Therefore, the development of surgical methods that enhance the accuracy of TME by means of innovative instruments and technologies is closely related to the results of rectal cancer treatment.

In the past, abdominoperineal resection was mostly performed for rectal cancer due to a lack of understanding of the pelvic anatomy and the technical difficulties of colorectal or coloanal anasto-

Received: Mar 18, 2020 - Revised: Jun 9, 2020 - Accepted: Jun 16, 2020 Correspondence to: Chang-Nam Kim, M.D.

Department of Surgery, Daejeon Eulji University Hospital, Eulji University School of Medicine, 95 Dunsanseo-ro, Seo-gu, Daejeon 35233, Korea

Tel: +82-42-259-1335, Fax: +82-42-259-1335

E-mail: kimcn7@gmail.com

ORCID: https://orcid.org/0000-0001-7781-9119

(C) 2020 The Korean Society of Coloproctology

This is an open-access article distributed under the terms of the Creative Commons Attribution NonCommercial License (https://creativecommons.org/licenses/by-nc/4.0) which permits unrestricted noncommercial use, distribution, and reproduction in any medium, provided the original work is properly cited. mosis. However, nowadays, sphincter-preserving surgery has become more frequent due to the introduction of TME by Heald et al. [1], the double stapling anastomosis technique, and neoadjuvant chemoradiotherapy for locoregional disease control [2,3].

TME is a gold-standard technique and an essential oncological principle for mid or low rectal tumors which involves dissection along a surgical plane ("holy plane") between the mesorectum and presacral fascia and preservation of the sacral vessels and hypogastric nerves. TME concept can promote structure preservation and allow for en bloc resection of tumor and lymphatic tissue, and better functional and oncological outcomes. For the upper rectal tumors, tumor-specific mesorectal excision which spares the distal rectum by dividing the mesorectum and rectum at least 4 to $5 \mathrm{~cm}$ below the lower margin of the tumor has been shown to be oncologically acceptable [4-6].

However, TME procedure for middle or low rectal tumors is not always successful due to significant problems such as narrow pelvis, bulky tumors, and surgeon's lack of understanding of TME anatomy. Therefore, high-quality TME is not often achieved, and this can jeopardize oncological results. Sound knowledge of the complex pelvic anatomy is needed to obtain a complete and highquality TME specimen, and well-designed instruments suitable for working in confined spaces with secure vision are required.

Since the Lacy trial [7] in 2002 reported safety and feasibility is- 
sue in the use of laparoscopy for colon cancer, the MRC-CLASSIC trial [8] in 2005, the COREAN trial [9] in 2010, and the COLOR II trial [10] in 2013, the representative multicenter randomized clinical trials for laparoscopic rectal cancer surgery have been conducted showing no differences in local recurrence or disease-free survival outcomes between laparoscopic surgery and open surgery. In contrast, the ACOSOG Z6051 [11] and ALaCaRT [12] trials used a composite assessment index (circumferential resection margin [CRM], distal resection margin [DRM], and completeness of TME) of successful rectal cancer resections but did not verify the noninferiority of laparoscopic surgery to open surgery. In the comparison of the ACOSOG and COREAN trials in which most patients received neoadjuvant chemoradiotherapy, short-term recovery and pathologic outcomes were better in the COREAN trial. This was considered due to differences in the body mass index (BMI) distribution of the patients and the experience of the surgeons. Currently, the safety of laparoscopic surgery for the treatment of rectal cancer is still controversial, and the National Comprehensive Cancer Network guidelines recommend that laparoscopic experts perform laparoscopic TME (LTME) limited to nonadvanced diseases.

Regardless of the surgical approach whether conventional open surgery or minimally invasive surgery, the principles of the TME are to keep accuracy, obtain completeness, and preserve autonomic nerves. In this respect, robotic surgical systems are expected to improve patient's functional and oncological outcomes than open or laparoscopic surgery using revolutionized technology to overcome many of the limits in laparoscopic surgical systems. In this paper, we reviewed current evidences and future perspectives on robotic TME (RTME) for rectal cancer.

\section{da Vinci SURGICAL SYSTEM FOR RECTAL CANCER SURGERY}

The da Vinci surgical system (Intuitive Surgical, Sunnyvale, CA, USA) was born out of the need to overcome the limitations of laparoscopic surgery compared to open surgery. Despite confirmation of its safety and noninferiority to open surgery and the benefits of early recovery and good cosmetic outcome, laparoscopic surgery is still more technically challenging than open surgery due to many drawbacks. The advantages of the robotic surgical systems include advanced stereoscopic 3-dimensional (3D) vision and absence of tremors and rotating and articulating movements, which allow for precise dissection with preservation of neurological and vascular structures in narrow confined spaces. The robotic systems also improve the placement and safety of intracorporeal sutures [13].

Robotic surgical systems were initially frequently used in the treatment of pelvic organ diseases such as gynecological tumors, urological tumors, and rectal cancer, which are located in narrow confined spaces and require technical skills [14]. In the study by Weber et al. [15] in 2002, early robotic surgery in the form of ro- botic-assisted laparoscopic colectomy was performed for intestinal mobilization, and laparoscopic surgery was performed for mesenteric division, intestinal transection, and anastomosis. The da Vinci S and da Vinci Si, which are early versions of the da Vinci surgical system, had relatively long docking times, were bulky, and had limited application in multi-quadrant surgery. The da Vinci $\mathrm{Xi}$, which is the latest version released in 2014, overcame the limitations of the $\mathrm{S}$ and $\mathrm{Si}$ versions with an easier docking process, wider range of motion, smaller robot arms, and a dynamic camera system that can be attached to any robotic arm. Thus, the new Xi version allows for easier multiquadrant access to different anatomical areas and for totally robotic surgery with single docking [16]. Recently the newly developed da Vinci SP system, robotic single-port platforms represent a viable option for advanced surgical procedure including urological and oropharyngeal procedures and begin to show its feasibility in the use for transanal approach rectal cancer surgery [17]. The da Vinci SP version has advantages with the 3 fully-wristed and elbowed instruments, and the fully-wristed endoscope through a single 2.5$\mathrm{cm}$ cannula which can reach anywhere within $360^{\circ}$ from the 1 port placement.

\section{ROBOTIC TME}

The initial use of RTME on 6 patients was reported in 2006, its operative outcomes were similar to those of open TME (OTME) and LTME, and it had the benefit of reducing the fatigue and stress of the surgeon during the procedures [18]. Kim et al. [19] also reported on the level of surgeon physical discomfort after robotic intersphincteric resection for rectal cancer (robotic surgery, $n=108$; open surgery, $n=114$ ). The score of Lawson et al. [20] for surgeon physical discomfort (none, 0 to severe, 5) was significantly lower in the robotic surgery group than in the open surgery group (robotic surgery, 1.4; open surgery, $3 ; \mathrm{P}<0.001$ ).

Unlike colon cancer, rectal cancer occurs deep in the narrow pelvis. As surgical dissection is continued downward, a more secure field of vision is required and tissue manipulation in the pelvic space using laparoscopic instruments becomes more difficult, and this can lead to tissue damage or tumor spread. Therefore, robotic systems with the advantages of 3D magnification and reduction of surgical stress and fatigue are very important and can impact surgical outcome. During the RTME procedure, the rectum and mesorectum are removed as a unit by meticulous sharp pelvic dissection between the visceral and parietal pelvic fascia under excellent vision and good illumination. The dissection plane can be easily set in the narrow pelvic space by continuous traction and countertraction using robotic instruments with the endo-wrist function, and the use of the third robotic arm for steady countertraction is essential for sharp and precise pelvic dissection. During anterior dissection between the seminal vesicle, prostate, or vagina and the Denonvilliers' fascia, the robotic system can set an accurate anatomical plane due to the stability of the camera plat- 
form and consistent steady countertraction using the third robotic arm. With regard to autonomic nerve preservation, the 3D magnified view of the robotic system can discriminate nerve structures better than in laparoscopic or open surgery. Compared to the laparoscopic approach, the above-mentioned advantages of the robotic approach are immense, especially when operating on low rectal cancers with unfavorable size and progression.

\section{PERIOPERATIVE OUTCOMES}

\section{Operating time and learning curve}

Since the introduction of the da Vinci system for rectal cancer, issues of safety and feasibility of the robotic system have been dealt with, but the problems of long operating time and high cost have not been solved yet. The reported mean operating time for RTME is 3 to 5 hours, and this shows that RTME tends to take longer than LTME. The perioperative outcomes including operating time are presented in Table 1 [21-30]. In general, most robotic colorectal surgeons are experts in LTME, but surgeons need additional time to overcome the learning curve of RTME. Beginners in robotic surgery undergo trial and error to create visual fields, experience movement limitation of robotic instruments and external collisions of robotic arms, and are unfamiliar with the surgical console.

Surgical outcomes are closely related to the experience of the surgeon. Therefore, since the introduction of the laparoscopic

Table 1. Perioperative outcomes after total mesorectal excision for patient with rectal cancer

\begin{tabular}{|c|c|c|c|c|c|c|c|c|c|c|c|c|}
\hline Study & Country & Design & Year & Operation & $\begin{array}{l}\text { Sample } \\
\text { size } \\
(\mathrm{n})\end{array}$ & $\begin{array}{l}\text { Tumor location } \\
(\%), \\
\text { upper/mid/low }\end{array}$ & $\begin{array}{l}\text { Operating } \\
\text { time } \\
\text { (min) }\end{array}$ & $\begin{array}{l}\text { Estimated } \\
\text { blood loss } \\
(\mathrm{mL})\end{array}$ & $\begin{array}{l}\text { Hospital } \\
\text { stay } \\
\text { (day) }\end{array}$ & $\begin{array}{c}\text { Conversion } \\
\text { rate } \\
(\%)\end{array}$ & $\begin{array}{c}\text { Overall } \\
\text { complication } \\
(\%)\end{array}$ & $\begin{array}{c}\text { Anastomotic } \\
\text { complication } \\
(\%)\end{array}$ \\
\hline $\begin{array}{l}\text { Pigazzi } \\
\text { et al. [21] }\end{array}$ & ] Multination & Retrospective & 2010 & RTME & 143 & $9.8 / 29.4 / 58.7$ & $297(90-660)^{\mathrm{a}}$ & $283(0-6,000)^{a}$ & $8.3(2-33)^{a}$ & 4.9 & 41.3 & 10.5 \\
\hline \multirow{2}{*}{$\begin{array}{l}\text { Baek et al. } \\
\text { [22] }\end{array}$} & USA & Retrospective & 2011 & RTME & 41 & $12.2 / 51.2 / 36.6$ & $296(150-520)^{b}$ & $200(20-2,000)^{!}$ & b $6.5(2-33)^{b}$ & 7.3 & 22.0 & 8.6 \\
\hline & & & & LTME & 41 & $31.7 / 43.9 / 24.4$ & $315(174-584)^{b}$ & $300(17-1,000)$ & b $6.6(3-20)^{b}$ & 22.0 & 26.8 & 2.9 \\
\hline \multirow{2}{*}{$\begin{array}{l}\text { Kwak et al. } \\
\text { [23] }\end{array}$} & Korea & Retrospective & 2011 & RTME & 59 & $10.2 / 49.9 / 40.7$ & $270(241-325)^{c}$ & NA & NA & 0 & 32.2 & 13.5 \\
\hline & & & & LTME & 59 & $10.2 / 49.1 / 40.7$ & $228(177-254)^{c}$ & NA & NA & 3.4 & 27.1 & 10.1 \\
\hline \multirow{2}{*}{$\begin{array}{c}\text { Kim et al. } \\
\text { [24] }\end{array}$} & Korea & Retrospective & 2012 & RTME & 100 & $15 / 41 / 44$ & $188 \pm 45$ & NA & $7.1 \pm 2.1$ & 0 & 26.0 & 2.0 \\
\hline & & & & OTME & 100 & $13 / 40 / 47$ & $103 \pm 23$ & NA & $6.9 \pm 1.5$ & 0 & 27.0 & 4.0 \\
\hline \multirow{2}{*}{$\begin{array}{l}\text { D'Annibale } \\
\text { et al. [25] }\end{array}$} & Italy & Retrospective & 2013 & RTME & 50 & $16 / 18 / 66$ & $270(240-315)^{c}$ & NA & $8(7-11)^{c}$ & 0 & 10.0 & 10.0 \\
\hline & & & & LTME & 50 & $42 / 24 / 34$ & $280(240-350)^{c}$ & NA & $10(8-14)^{c}$ & 12.0 & 22.0 & 14.0 \\
\hline \multirow{2}{*}{$\begin{array}{l}\text { Kang et al. } \\
\text { [26] }\end{array}$} & Korea & Retrospective & 2013 & RTME & 165 & $34.5 / 65.5^{d}$ & $309.7 \pm 115.2$ & $133.0 \pm 192.3$ & $10.8 \pm 5.5$ & 0.6 & 20.6 & 7.3 \\
\hline & & & & LTME & 165 & $32.7 / 67.3^{d}$ & $277.8 \pm 81.9$ & $140.1 \pm 216.4$ & $13.5 \pm 9.2$ & 1.8 & 27.9 & 10.8 \\
\hline \multirow{2}{*}{$\begin{array}{c}\text { Park et al. } \\
\text { [27] }\end{array}$} & Korea & Retrospective & 2013 & RTME & 40 & NA & $233.5 \pm 57.5$ & $45.7 \pm 40.0$ & $10.6 \pm 4.2$ & 0 & 15.0 & 7.5 \\
\hline & & & & LTME & 40 & NA & $185.4 \pm 72.8$ & $59.2 \pm 35.8$ & $11.3 \pm 3.6$ & 0 & 12.5 & 5.0 \\
\hline $\begin{array}{l}\text { Kim et al. } \\
\text { [28] }\end{array}$ & Korea & Retrospective & 2016 & RTME & 60 & 20.0/28.3/51.7 & $466.8 \pm 115.6$ & $74.2 \pm 50.0$ & $8.6 \pm 2.4$ & 0 & 15.0 & 6.7 \\
\hline \multirow{2}{*}{$\begin{array}{l}\text { Jayne et al. } \\
\text { [29] }\end{array}$} & . Multination & RCT & 2017 & RTME & 237 & $30.1 / 45.3 / 24.2$ & $298.5 \pm 88.7$ & NA & $8.0 \pm 5.8$ & 8.1 & 33.1 & $14.8^{\mathrm{e}}$ \\
\hline & & & & LTME & 234 & $30.0 / 43.0 / 26.5$ & $261.0 \pm 83.2$ & NA & $8.2 \pm 6.0$ & 12.2 & 31.7 & $17.4^{\mathrm{e}}$ \\
\hline \multirow{2}{*}{$\begin{array}{r}\text { Fransgaard } \\
\text { et al. [30] }\end{array}$} & Denmark & Retrospective & 2018 & RTME & 706 & NA & NA & NA & NA & 6.7 & 21.0 & NA \\
\hline & & & & LTME & 3,934 & NA & NA & NA & NA & 12.0 & 22.6 & NA \\
\hline
\end{tabular}

Values are presented as number only, mean \pm standard deviation, ${ }^{a}$ mean (range), ${ }^{\mathrm{b}}$ median (range), or ${ }^{\mathrm{c}}$ median (interquartile range).

RTME, robotic total mesorectal excision; LTME, laparoscopic total mesorectal excision; OTME, open total mesorectal excision; NA, not applicable; RCT, randomized controlled trial.

dUpper/low. ${ }^{e}$ Gastrointestinal complications including anastomotic leak within 30 days postoperatively. 
surgery, shortening the learning curve period and operating time of minimally invasive surgery have been great concerns. According to reports, the learning curve of laparoscopic colorectal surgery is 30 to 70 cases [31-34]. Technical proficiency in robotic surgery is achieved after 20 cases because of the technical advantages of robotic surgery over laparoscopy, and it shortens the learning curve of TME [35]. Before the release of da Vinci Xi, the docking process was regarded as a pitfall and robotic rectal surgeons tried to improve it. Therefore, various methods of approach were developed for RTME using the different trocar positions and docking processes of the da Vinci S and Si versions. The hybrid method of RTME entails using laparoscopy for the step of inferior mesenteric artery (IMA) ligation with or without splenic flexure mobilization, which can help shorten the docking process, while fully robotic surgery with single docking was developed and implemented by surgeons. Trocar placement can vary depending on surgeon preference, patient anatomical characteristics, and intraoperative conditions such as difficulty of exposure of the inferior mesenteric vein or splenic flexure, unfavorable localization of the small bowel, visceral obesity, and need for multiple positional changes [16]. Therefore, optimal trocar placement and docking procedures are of prime concern for beginners in robotic surgery. Since the introduction of the da Vinci Xi version, the operating time and learning curve of RTME have decreased to an acceptable range compared to LTME due to improvements in the docking process and the excellent implementation of fully robotic procedures [16]. Basic robotic surgical skill set can be acquired in the simulation laboratory, and commercially available simulators have been shown to be capable of assessing robotic surgical skills [36]. Currently, the learning curve and operating time of RTME are no longer problems for laparoscopic experts, and totally robotic procedures using the Xi version have become easier than before for beginners. Interestingly, a study reported that no difference in adaptation to robotic procedures was observed between beginners in robotic surgery with experience in laparoscopic surgery and those without such experience [37].

\section{Conversion rate}

The conversion rate of LTME has been investigated and the distribution has been shown to vary even in randomized clinical trials. The COREAN trial [9] reported a conversion rate lower than that reported in Western studies, and this may be due to the relatively lower BMI and fewer patients with obesity in the trial. Clinically, conversion rates are important with regard to oncological outcomes because, in general, the abilities of the surgeon and the assistant, patient characteristics, and tumor characteristics can affect the radicality of the surgical procedure and the conversion rate [38]. In the initial periods of RTME, its conversion rate received attention for having a range of $0 \%$ to $7.3 \%$, which was considered low compared to the conversion rate of LTME that ranged from $0 \%$ to $22 \%$ [39]. Trastulli et al. [40] reviewed 8 studies for the conversion rates of laparoscopic and robotic rectal cancer surgeries and reported mean conversion rates of 2\% for RTME and 7.5\% for LTME. It was considered that the technological advantages of the robotic surgical system can make RTME easier and prevent conversion to open surgery. Conversion rate was recently assessed in the ROLARR trial [29] and conversion rates of $8.1 \%$ for robotic surgery and $12.2 \%$ for laparoscopic surgery were reported, but there was no significant difference between the groups of patients that underwent robotic surgery or laparoscopic surgery $(\mathrm{P}=0.16)$. Interestingly, although the ROLARR trial statistically failed to show a lower conversion rate in the robotic group, subgroup analysis confined to male patients revealed a significantly lower conversion rate in the robotic group (robotic surgery group, 8.7\%; laparoscopic surgery group, $16 \% ; \mathrm{P}=0.0429$ ). This result was probably because the pelvises of the male patients are narrower than those of the female patients. This relates to the technical difficulty of laparoscopic surgery, and the limitations of laparoscopic surgery are overcome by robotic surgery. Although not statistically significant, conversion rates in patients with obesity (robotic surgery, 18.9\%; laparoscopic surgery, $27.8 \% ; \mathrm{P}=0.2944$ ) and patients who underwent low anterior resection (robotic surgery, 7.2\%; laparoscopic surgery, $13.3 \% ; \mathrm{P}=0.0909$ ) tended to be lower in the robotic group than in the laparoscopic group. Although further studies with larger study populations seem to be necessary, robotic surgery may help overcome the technical difficulties of laparoscopic surgery in men, patients with obesity, and patients scheduled to undergo low anterior resection. The conversion rates of RTME are presented in Table 1.

\section{Voiding and sexual functions}

Urinary and sexual dysfunctions are major concerns after rectal cancer surgery, and they are caused by direct or indirect injury to the pelvic autonomic nerves during rectal dissection. These functional sequelae greatly impact the quality of life of patients. Meticulous dissection along the surgical plane of TME between the mesorectum and pelvic fascia can be performed to completely resect the tumor, but nerve tissue around the surgical plane of the TME can easily be affected or damaged during the procedure. Therefore, nerve preservation during TME is vital for the quality of life of patients with rectal cancer, especially for the preservation of voiding and sexual functions. In the COREAN trial [9], LTME was shown to be associated with more acute voiding difficulties requiring catheter insertion than OTME (open surgery, 4.1\%; laparoscopic surgery, $10 \% ; \mathrm{P}=0.034$ ). The researchers explained that these results may be related to the broader retractor used in open surgery that results in less severe neuropraxia than in laparoscopic surgery where smaller instruments are used for retraction. However, these functional disturbances were observed in the short-term period and were transient.

Robotic surgery involves use of instruments with different action mechanisms and offers good visual assessment to discriminate nerve tissues. In a phase II randomized trial that compared RTME and LTME, it was found that sexual function at 12 postoperative 
months was significantly better in the RTME group than in the LTME group (mean scores of the colorectal cancer-specific quality of life questionnaire module [QLQ-CR38]: RTME, 35.2 and LTME, 23; $\mathrm{P}=0.032$ ) [41]. In a comparative study, the RTME group showed early recovery with normal voiding and sexual function within 6 postoperative months, whereas the LTME group showed functional recovery after 12 postoperative months [42]. In a case-matching comparison of male patients, bladder dysfunction was similar in the RTME and LTME groups for 12 months, but recovery from erectile dysfunction occurred earlier in the RTME group than in the LTME group [43]. Although individual study showed slightly different outcome profiles, the results were favorable in the RTME group in terms of preservation of voiding and sexual functions. However, in the ROLARR trial [29], no significant difference in bladder dysfunction and sexual dysfunction was observed 30 days and 6 months after surgery between the RTME and LTME groups.

In general, there are several determining factors of genitourinary dysfunction after rectal cancer surgery, and they include tumor location, neoadjuvant chemoradiotherapy, preoperative baseline function, and extent of nerve preservation during surgery [44-47]. In rectal cancer surgery, genitourinary dysfunction is often caused by nerve damage in the following surgical procedures: IMA ligation around the root of IMA and mesorectal mobilization which cause sympathetic nerve injury and result in retrograde ejaculation and urinary incontinence; low rectum and lateral wall dissection which causes hypogastric plexus and nervi erigentes injury and results in impaired ejaculation and detrusor contractility, erectile dysfunction, and dyspareunia; and dissection around the anterior side of the Denonvilliers' fascia which may cause neurovascular bundle damage and result in male erectile dysfunction [48-52].

The visual capacity to distinguish nerves from other structures is better in robotic surgery than in laparoscopic surgery. The 3D magnified visualization through the surgeon-controlled camera system can provide a stable surgeon-oriented view and improved anatomical discrimination for nerve preservation such that precise dissection is possible. The endo-wristed instruments with hand tremor filtering on each of the 3 arms can provide a stable surgical approach with excellent traction-countertraction. The articulating movement from the surgical console is ergonomic and can reduce unfavorable manipulation, injury, and surgeon fatigue, thereby improving functional outcome.

\section{Anastomotic leakage}

One of the major complications of rectal cancer surgery is anastomotic leakage. The incidence of anastomotic leakage as reported in literature is $3.9 \%$ to $19.2 \%$ [53-59]. It has been reported that the multivariable factors associated with anastomotic leakage after rectal cancer surgery include patients with diabetes mellitus, American Society of Anesthesiologists physical status classification, intake of steroid medication, previous radiation therapy, surgical approach (minimally invasive or open), insufficient blood supply or tension at the site of anastomosis, and technical error during stapling [60-66]. A comparative study of RTME $(n=56)$ and LTME $(n=57)$ reported that the outcomes of serious complications were better in RTME than in LTME (robotic surgery, 5.4\%; laparoscopic surgery, 19.3\%; $\mathrm{P}=0.025)$ and include anastomotic leakage (robotic surgery, 1/56 [1.8\%]; laparoscopic surgery, 4/57 [7.0\%]) [39].

Suggested advantages of robotic TME regarding anastomotic leakage may be due to the technological advantages of RTME described below, which prevent anastomotic leakage. First, due to the superior visualization of blood and lymphatic flow in the robotic indocyanine green fluorescent view, robotic systems have an improved ability to preserve blood flow; therefore, surgeons can determine the perfusion status at the site of anastomosis and the range of distal or proximal transection level [67]. Second, intracorporeal reinforcement sutures can be more easily placed with the articulating endo-wrist of robotic systems. Third, IMA low ligation for better blood supply can be easily performed with the robotic system. Lastly, by reducing the number of firing staplers, the endo-wrist stapler of the robotic system can reduce transection error [68]. The anastomotic complication rates of RTME are presented in Table 1.

\section{PATHOLOGIC RESULTS}

Besides the TNM staging and tumor biology, the surgical outcomes of DRM, CRM, and completeness of the TME have been considered as a major prognostic factor. The optimal length of DRM for oncologic safety in sphincter-preserving low rectal cancer surgery is still controversial. The 2 -cm length is clinically acceptable because the intramural tumor spread rarely exceed 1 to 2 $\mathrm{cm}$ in distance $[69,70]$. The oncologic significance of the DRM, CRM, or TME completeness is that these factors are closely related to the local tumor recurrence and can influence the oncologic outcomes. Various factors influence these pathologic results including the neoadjuvant chemoradiation therapy, narrow pelvis, bulky tumor size, existence of perirectal lymph node metastasis, measurement methods, and surgical approach methods of minimally invasive or open surgery [69]. Between conventional open surgery and minimally invasive laparoscopic or robotic surgery for rectal cancer, these pathologic outcomes play a role as the indicator of the noninferior measurement of each operation method. The TME completeness was better observed in open surgery in ALaCaRT trial (TME completeness, $92 \%$ vs. $87 \%$ ) [12] and ACOSOG trial (complete TME, 95\% vs. 92\%) [11]. In robotic surgery, although the DRM and CRM data were slightly different in each independent study (Table 2 [21, 28, 41, 71-82]), many studies of the RTME have been reported as showing better results than LTME in TME completeness. Allemann et al. [83] reported better results of RTME compared with LTME in TME completeness (95\% vs. 55\%) and Kim et al. [84] also reported significantly 


\section{Coloproctology}

Table 2. Short- and long-term oncological outcomes after total mesorectal excision for patient with rectal cancer

\begin{tabular}{|c|c|c|c|c|c|c|c|c|c|c|c|c|}
\hline Study & Year & Operation & $\begin{array}{l}\text { Sample } \\
\text { size (n) }\end{array}$ & $\begin{array}{c}\text { Tumor } \\
\text { Iocation from } \\
\text { AV }(\mathrm{cm})\end{array}$ & $\begin{array}{l}\text { Follow-up } \\
\text { (mo) }\end{array}$ & $\begin{array}{l}\text { PCRT } \\
(\%)\end{array}$ & $\begin{array}{c}\text { CRM } \\
\text { positivity } \\
(\%)\end{array}$ & $\begin{array}{l}\text { Length of } \\
\text { DRM }(\mathrm{cm})\end{array}$ & $\operatorname{LR}(\%)^{\mathrm{a}}$ & DR $(\%)^{\mathrm{a}}$ & OS $(\%)^{\mathrm{a}}$ & DFS $(\%)^{\mathrm{a}}$ \\
\hline \multicolumn{13}{|c|}{ Short-term oncological outcomes } \\
\hline Pigazzi et al. [21] & 2010 & RTME & 143 & NA & 17.4 & 65.1 & 0.7 & 2.9 & 1.5 & NA & 97.0 & 77.6 \\
\hline Baek et al. [71] & 2010 & RTME & 64 & NA & 20.2 & 85.9 & 0 & 3.4 & 3.1 & NA & 96.2 & 73.7 \\
\hline Baik et al. [72] & 2013 & RTME & 370 & NA & 26.5 & 21.1 & 5.7 & $2.5 \pm 1.4$ & 3.6 & NA & 93.1 & 79.2 \\
\hline Kim et al. [28] & 2016 & RTME & 60 & NA & 48.5 & 36.7 & 11.7 & $3.1 \pm 1.7$ & $1.9^{b}$ & $26.4^{b}$ & $87.7^{\mathrm{b}}$ & $72.8^{b}$ \\
\hline Kim et al. [73] & 2017 & RTME & 310 & $3.3 \pm 1.7$ & 36.0 & 48.4 & 1.0 & 1.4 & 3.6 & 17.0 & 91.1 & 79.5 \\
\hline \multirow[t]{2}{*}{ Kim et al. [41] } & 2018 & RTME & 66 & NA & 12.0 & 77.3 & 6.1 & 1.5 & NA & NA & NA & NA \\
\hline & & LTME & 73 & NA & 12.0 & 79.5 & 5.5 & 0.7 & NA & NA & NA & NA \\
\hline \multirow[t]{2}{*}{ Lee et al. [74] } & 2018 & RTME & 24 & $5.2 \pm 1.9$ & 22.0 & 50.0 & 8.3 & 1.9 & 0 & 4.2 & NA & NA \\
\hline & & L-TaTME & 21 & $6.1 \pm 1.6$ & 20.1 & 66.7 & 4.8 & 2.2 & 4.8 & 9.5 & NA & NA \\
\hline Sammour et al. [75] & 2018 & RTME & 267 & NA & 23.8 & 75.0 & 2.5 & $>1.0$ & 2.4 & 16.9 & 87.0 & 82.0 \\
\hline \multicolumn{13}{|c|}{ Long-term oncological outcomes } \\
\hline Pai et al. [76] & 2015 & RTME & 101 & NA & 34.9 & 74.3 & 5.0 & $3.5 \pm 2.7$ & 4.0 & NA & 90.1 & 79.2 \\
\hline \multirow[t]{2}{*}{ Yoo et al. [77] } & 2015 & RTME & 44 & $3.2 \pm 0.7$ & 36.5 & 54.5 & 9.1 & 1.3 & NA & NA & 95.2 & 76.7 \\
\hline & & LTME & 26 & $3.7 \pm 0.8$ & 36.5 & 26.9 & 19.2 & 1.6 & NA & NA & 88.5 & 75.0 \\
\hline \multirow[t]{2}{*}{ Feroci et al. [78] } & 2016 & RTME & 53 & $8(4-12)$ & 37.0 & 49.1 & 0 & $2.5(0.5-10)$ & 1.9 & 17.0 & 90.2 & 79.2 \\
\hline & & LTME & 58 & $8(3-12)$ & 37.0 & 43.1 & 1.7 & $1.5(0.5-5.5)$ & 5.2 & 8.6 & 90.0 & 83.4 \\
\hline \multirow[t]{2}{*}{ Lim et al. [79] } & 2017 & RTME & 74 & $5.3 \pm 2.3$ & 56.1 & 100 & 4.0 & $1.7 \pm 1.4$ & 2.7 & 15.6 & 90.0 & 76.8 \\
\hline & & LTME & 64 & $6.7 \pm 2.6$ & 56.1 & 100 & 1.6 & $2.2 \pm 1.5$ & 6.3 & 18.9 & 93.3 & 76.0 \\
\hline \multirow[t]{2}{*}{ Law et al. [80] } & 2017 & RTME & 220 & $7(0-12)$ & 31.4 & 41.4 & 4.1 & 3 & 5.2 & NA & 71.8 & 81.9 \\
\hline & & LTME & 171 & $8(0-12)$ & 31.4 & 29.2 & 8.2 & 3 & 5.2 & NA & 74.3 & 80.0 \\
\hline \multirow[t]{2}{*}{ Kim et al. [81] } & 2020 & RTME $^{c}$ & 488 & $3.3 \pm 1.7$ & 60.0 & 50.0 & 1.4 & $1.7 \pm 1.1^{\mathrm{e}}$ & 2.5 & NA & 86.7 & 80.7 \\
\hline & & RTME $^{d}$ & 409 & $8.6 \pm 2.0$ & 60.0 & 7.1 & 2.0 & $3.4 \pm 1.5$ & 2.9 & NA & 84.2 & 78.5 \\
\hline \multirow[t]{2}{*}{ Asoglu et al. [82] } & 2020 & RTME & 14 & $<10$ & 87.0 & 100 & 0.5 & 2.7 & 3.8 & 2.5 & 83.3 & 81.8 \\
\hline & & LTME & 65 & $<10$ & 87.0 & 100 & 1.8 & 1.5 & 6.3 & 20.1 & 75.0 & 74.4 \\
\hline
\end{tabular}

Values are presented as number only, mean \pm standard deviation, or median (range) unless otherwise denoted.

AV, anal verge; PCRT, preoperative chemoradiotherapy; CRM, circumferential resection margin; DRM, distal resection margin; LR, local recurrence; DR, distant recurrence; OR, overall survival; DFS, disease-free survival; RTME, robotic total mesorectal excision; LTME, laparoscopic total mesorectal excision; L-TaTME, laparoscopic transanal total mesorectal excision; NA, not applicable.

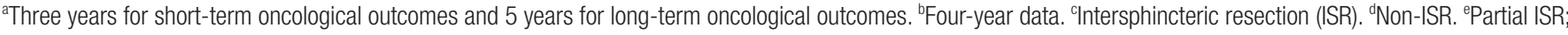
subtotal ISR, $1.2 \pm 0.9$; total ISR, $1.2 \pm 1.0$.

better TME specimen quality in RTME group than LTME (97\% vs. 91\%). Barnajian et al. [85] reported a matched comparison of the first 20 cases of RTME. Although the quality of TME was not significantly different in the OTME, LTME, and RTME groups during the learning curve of RTME $(\mathrm{P}=0.153)$, the depth of CRM was significantly greater in the RTME group (OTME, 8 $\mathrm{mm}$; LTME, $4 \mathrm{~mm}$; RTME, $10.5 \mathrm{~mm}$; $\mathrm{P}=0.026$ ). The researchers reckoned that the greater depth of CRM in the RTME group during the learning curve of RTME may be related to the ability of the robotic instruments to overcome the fulcrum effect produced by trocars during LTME, and not the ability and skills of the surgeon. So, to prove the superiority of RTME in these pathologic re- sults and short-term oncologic outcome compared to LTME, more clinical trials are currently required.

\section{ONCOLOGICAL OUTCOMES}

Since the introduction of the da Vinci system for rectal cancer surgery, many studies have confirmed the safety and feasibility of the robotic surgical system and reported the advantage of early functional recovery. However, evidence that robotic surgery has improved oncological outcomes more than laparoscopic or open surgery is still insufficient. Oncological outcomes are dependent on a variety of factors during treatment. Of the several multimodal 
treatments for rectal cancer, preoperative disease control with neoadjuvant chemoradiotherapy and postoperative control with adjuvant chemotherapy have regimens that are standardized according to guidelines. These perioperative management protocols have little impact on oncological outcomes, but there are no guarantees of complete locoregional control without tumor splitting or spread during TME with the operative procedures. Therefore, the surgical procedure of TME can be considered as having a significant impact on oncological outcomes. Since the introduction of the da Vinci system, the technological advantages of RTME over LTME have been considered to have a positive impact on oncological outcomes. Robotic surgery promotes better tumor control with a better visual approach during IMA ligation, splenic flexure mobilization, and TME. Despite these potential benefits of RTME, the superiority of oncological outcomes after RTME has not yet been proven. Studies including randomized clinical trials $[29,41]$ and case-matched analyses have only reported noninferior short-term operative or pathologic outcomes of RTME compared to those of LTME or OTME [22, 23, 26]. Kim et al. [86] compared the survival outcomes of the following 3 groups: OTME $(\mathrm{n}=1,095)$, LTME $(\mathrm{n}=486)$, and RTME $(\mathrm{n}=533)$. They reported that no significant differences were observed in the rates of 3-year local recurrence (2.5\% to $3.4 \% ; \mathrm{P}=0.85$ ), overall survival (91.9\% to $94.6 \% ; \mathrm{P}=0.352)$, and disease-free survival $(82.2 \%$ to 83.1\%; $\mathrm{P}=0.944$ ) between the 3 groups. Interestingly, multivariable analysis revealed that RTME is a significant determinant of sphincter-preserving operations (OTME + LTME, 91.8\%; RTME, 95.1\%; $\mathrm{P}<0.001)$ regardless of tumor stage and location. In a phase II randomized clinical trial, the outcomes of resection margins, number of harvested lymph nodes, and TME quality were found to be similar between RTME and LTME (RTME: complete, $80.3 \%$ and nearly complete, $18.2 \%$; LTME: complete, $78.1 \%$ and nearly complete, 21.9\%) [41]. The short-term and long-term oncological outcomes of RTME are presented in Table 2.

\section{ROBOTIC TRANSANAL TOTAL MESORECTAL EXCISION}

Robotic transanal TME (TaTME) was developed for more secure distal transection margins and to allow for distal dissection through the anal canal. TaTME also follows the principle of TME described by Heald [1], but the direction of dissection is countercurrent. Before the current concept of TaTME, the transanal approach to rectal cancer surgery was based on the transanal abdominal transanal (TATA) resection performed by Marks et al. [87]. The next development was the introduction of transanal endoscopic microsurgery (TEM) for early tumors. However, the application of TEM was temporary and limited due to the poor cost-benefit of TEM devices [88]. Transanal minimally invasive surgery (TAMIS), which uses the minimally invasive single-port laparoscopic platform, was developed recently and has gained popularity [89].
TaTME is an approach that combines the transabdominal and TAMIS approaches of TME. It has the advantages of easy access to the low rectum, improved TME quality, and adequate DRM [90]. In TaTME procedures, minimally invasive single-port laparoscopic platforms have technical limitations similar to those of single-port laparoscopic surgery; therefore, beginners have to overcome the learning curve of single-port surgery and understand the new countercurrent anatomy of the pelvis. Owing to its technological advantages, robotic TaTME may be more beneficial than laparoscopic TaTME. The Xi version of the da Vinci system, which has the capability for reduced-port or single-incision plus one-port surgery, is most beneficial for TaTME. The newly developed da Vinci SP system provides more revolutionized options for TaTME and endoluminal transanal surgery. Marks et al. [17] performed transanal rectal resections on cadaveric models using the da Vinci SP surgical system, and the surgical system performed well for all types of surgery. The researchers reported that the SP system has the potential to expand transanal surgery to the next step beyond TaTME, which is natural orifice transluminal endoscopic surgery (NOTES). Evidences for TaTME and robotic TaTME using da Vinci SP surgical system are currently lacking. However, given the potentials of the da Vinci SP surgical system, it is expected to be the system of choice for rectal cancer surgery in the future.

\section{THE FUTURE PERSPECTIVES OF ROBOTIC SURGERY FOR RECTAL CANCER}

Several new robotic system technologies have recently been developed and tried in TME. Continuous neuromonitoring during TME has been tried by many surgeons with different platforms to preserve nerve tissue during rectal cancer surgery and improve functional outcomes [91]. RTME has been successfully performed with a neuromapping device on a da Vinci Xi system as intraoperative pelvic neuromapping with real-time electromyography and cystomanometry signals transmitted to a surgical console in multi-image views [92]. Although the methods for preserving pelvic neuromuscular functions are limited and still in the early stages, they are expected to gain popularity among colorectal surgeons in the future. Imaging-guided surgery using navigation systems has also been tried and is under development. Robotic-assisted stereotactic real-time navigation surgery using the da Vinci Xi platform and navigating interface has been attempted [93]. Although it is generally not a usable platform due to many limitations, navigating with the surgical system will further enhance the surgeon's perception in future surgeries.

For over 20 years, da Vinci surgical systems had a monopoly in the field of minimally invasive robotic surgery. Many competitors of Intuitive Surgical have been trying to develop various types of minimally invasive robotic surgical platforms in the hope of sharing the robotic surgical market or replacing da Vinci surgical systems. They include Telelap ALF-X/Senhance surgical system 
(TransEntrix Inc., Morrisville, NC, USA), Versius (CMR Surgical, Cambridge, UK), MiroSure (Medtronic, Dublin, Ireland), REVOI (Meere Company, Hwaseong, Korea), and Surgery 4.0-digital surgery (Verb Surgical Inc., Santa Clara, CA, USA) [94]. Each platform has its own characteristics and was designed for a specific situation. Robotic systems for single-port surgery and NOTES platforms have also been developed, and they include the following: SurgiBot (TransEntrix Inc.), da Vinci SP system, SPORT (Titan Medical, Toronto, ON, Canada), MIVR (Virtual Incision, Lincoln, NE, USA), and MASTER (EndoMaster Pte Ltd., Singapore) [94]. Newly developed or developing robotic systems will be of great help in the field of minimally invasive surgery including TME for rectal cancer.

One last revolutionary idea is the use of artificial intelligence in surgical robotic systems. Deep learning (also known as machine learning) of the artificial intelligence is expressed using mathematical algorithms that enhance learning through experience and has the following 3 categories; unsupervised, supervised, and reinforcement learning [95]. It will be an epoch in history if surgical robots with machine-learning functions are created.

\section{CONCLUSION}

To improve the outcome of rectal cancer surgery, complete TME should be safely and accurately performed. However, the laparoscopic approach is still challenging because of technical limitations in the narrow deep pelvis. Although 3D camera systems and articulating instruments are used in laparoscopic surgery, robotic surgical systems are better at maintaining TME principles, especially considering the technical aspects of rectal cancer surgery. The application of various robotic surgical systems in TME using the transabdominal or transanal approach will greatly contribute to favorable outcomes of minimally invasive rectal cancer surgery in the future.

\section{CONFLICT OF INTEREST}

No potential conflict of interest relevant to this article was reported.

\section{REFERENCES}

1. Heald RJ, Husband EM, Ryall RD. The mesorectum in rectal cancer surgery: the clue to pelvic recurrence? Br J Surg 1982;69:613-6.

2. MacFarlane JK, Ryall RD, Heald RJ. Mesorectal excision for rectal cancer. Lancet 1993;341:457-60.

3. Kapiteijn E, Marijnen CA, Nagtegaal ID, Putter H, Steup WH, Wiggers T, et al. Preoperative radiotherapy combined with total mesorectal excision for resectable rectal cancer. N Engl J Med 2001;345:638-46.

4. Monson JR, Weiser MR, Buie WD, Chang GJ, Rafferty JF, Buie WD, et al. Practice parameters for the management of rectal can- cer (revised). Dis Colon Rectum 2013;56:535-50.

5. Zaheer S, Pemberton JH, Farouk R, Dozois RR, Wolff BG, Ilstrup D. Surgical treatment of adenocarcinoma of the rectum. Ann Surg 1998;227:800-11.

6. Kim NK, Baik SH, Seong JS, Kim H, Roh JK, Lee KY, et al. Oncologic outcomes after neoadjuvant chemoradiation followed by curative resection with tumor-specific mesorectal excision for fixed locally advanced rectal cancer: impact of postirradiated pathologic downstaging on local recurrence and survival. Ann Surg 2006;244:1024-30.

7. Lacy AM, García-Valdecasas JC, Delgado S, Castells A, Taurá P, Piqué JM, et al. Laparoscopy-assisted colectomy versus open colectomy for treatment of non-metastatic colon cancer: a randomised trial. Lancet 2002;359:2224-9.

8. Guillou PJ, Quirke P, Thorpe H, Walker J, Jayne DG, Smith AM, et al. Short-term endpoints of conventional versus laparoscopicassisted surgery in patients with colorectal cancer (MRC CLASICC trial): multicentre, randomised controlled trial. Lancet 2005; 365:1718-26.

9. Kang SB, Park JW, Jeong SY, Nam BH, Choi HS, Kim DW, et al. Open versus laparoscopic surgery for mid or low rectal cancer after neoadjuvant chemoradiotherapy (COREAN trial): short-term outcomes of an open-label randomised controlled trial. Lancet Oncol 2010;11:637-45.

10. van der Pas MH, Haglind E, Cuesta MA, Fürst A, Lacy AM, Hop WC, et al. Laparoscopic versus open surgery for rectal cancer (COLOR II): short-term outcomes of a randomised, phase 3 trial. Lancet Oncol 2013;14:210-8.

11. Fleshman J, Branda M, Sargent DJ, Boller AM, George V, Abbas M, et al. Effect of laparoscopic-assisted resection vs open resection of stage II or III rectal cancer on pathologic outcomes: the ACOSOG Z6051 randomized clinical trial. JAMA 2015;314:1346-55.

12. Stevenson AR, Solomon MJ, Lumley JW, Hewett P, Clouston AD, Gebski VJ, et al. Effect of laparoscopic-assisted resection vs open resection on pathological outcomes in rectal cancer: the ALaCaRT randomized clinical trial. JAMA 2015;314:1356-63.

13. Stefanidis D, Wang F, Korndorffer JR Jr, Dunne JB, Scott DJ. Robotic assistance improves intracorporeal suturing performance and safety in the operating room while decreasing operator workload. Surg Endosc 2010;24:377-82.

14. Ahlering TE, Skarecky D, Lee D, Clayman RV. Successful transfer of open surgical skills to a laparoscopic environment using a robotic interface: initial experience with laparoscopic radical prostatectomy. J Urol 2003;170:1738-41.

15. Weber PA, Merola S, Wasielewski A, Ballantyne GH. Teleroboticassisted laparoscopic right and sigmoid colectomies for benign disease. Dis Colon Rectum 2002;45:1689-94.

16. Morelli L, Di Franco G, Guadagni S, Rossi L, Palmeri M, Furbetta $\mathrm{N}$, et al. Robot-assisted total mesorectal excision for rectal cancer: case-matched comparison of short-term surgical and functional outcomes between the da Vinci Xi and Si. Surg Endosc 2018;32: 589-600. 
17. Marks J, Ng S, Mak T. Robotic transanal surgery (RTAS) with utilization of a next-generation single-port system: a cadaveric feasibility study. Tech Coloproctol 2017;21:541-5.

18. Pigazzi A, Ellenhorn JD, Ballantyne GH, Paz IB. Robotic-assisted laparoscopic low anterior resection with total mesorectal excision for rectal cancer. Surg Endosc 2006;20:1521-5.

19. Kim JC, Lim SB, Yoon YS, Park IJ, Kim CW, Kim CN. Completely abdominal intersphincteric resection for lower rectal cancer: feasibility and comparison of robot-assisted and open surgery. Surg Endosc 2014;28:2734-44.

20. Lawson EH, Curet MJ, Sanchez BR, Schuster R, Berguer R. Postural ergonomics during robotic and laparoscopic gastric bypass surgery: a pilot project. J Robot Surg 2007;1:61-7.

21. Pigazzi A, Luca F, Patriti A, Valvo M, Ceccarelli G, Casciola L, et al. Multicentric study on robotic tumor-specific mesorectal excision for the treatment of rectal cancer. Ann Surg Oncol 2010;17:161420.

22. Baek JH, Pastor C, Pigazzi A. Robotic and laparoscopic total mesorectal excision for rectal cancer: a case-matched study. Surg Endosc 2011;25:521-5.

23. Kwak JM, Kim SH, Kim J, Son DN, Baek SJ, Cho JS. Robotic vs laparoscopic resection of rectal cancer: short-term outcomes of a case-control study. Dis Colon Rectum 2011;54:151-6.

24. Kim JC, Yang SS, Jang TY, Kwak JY, Yun MJ, Lim SB. Open versus robot-assisted sphincter-saving operations in rectal cancer patients: techniques and comparison of outcomes between groups of 100 matched patients. Int J Med Robot 2012;8:468-75.

25. D’Annibale A, Pernazza G, Monsellato I, Pende V, Lucandri G, Mazzocchi P, et al. Total mesorectal excision: a comparison of oncological and functional outcomes between robotic and laparoscopic surgery for rectal cancer. Surg Endosc 2013;27:1887-95.

26. Kang J, Yoon KJ, Min BS, Hur H, Baik SH, Kim NK, et al. The impact of robotic surgery for mid and low rectal cancer: a casematched analysis of a 3-arm comparison-open, laparoscopic, and robotic surgery. Ann Surg 2013;257:95-101.

27. Park SY, Choi GS, Park JS, Kim HJ, Ryuk JP. Short-term clinical outcome of robot-assisted intersphincteric resection for low rectal cancer: a retrospective comparison with conventional laparoscopy. Surg Endosc 2013;27:48-55.

28. Kim CN, Bae SU, Lee SG, Yang SH, Hyun IG, Jang JH, et al. Clini$\mathrm{cal}$ and oncologic outcomes of totally robotic total mesorectal excision for rectal cancer: initial results in a center for minimally invasive surgery. Int J Colorectal Dis 2016;31:843-52.

29. Jayne D, Pigazzi A, Marshall H, Croft J, Corrigan N, Copeland J, et al. Effect of robotic-assisted vs conventional laparoscopic surgery on risk of conversion to open laparotomy among patients undergoing resection for rectal cancer: the ROLARR randomized clinical trial. JAMA 2017;318:1569-80.

30. Fransgaard T, Pinar I, Thygesen LC, Gögenur I. Association between robot-assisted surgery and resection quality in patients with colorectal cancer. Surg Oncol 2018;27:177-84.

31. Schlachta CM, Mamazza J, Seshadri PA, Cadeddu M, Gregoire R,
Poulin EC. Defining a learning curve for laparoscopic colorectal resections. Dis Colon Rectum 2001;44:217-22.

32. Dinçler S, Koller MT, Steurer J, Bachmann LM, Christen D, Buchmann P. Multidimensional analysis of learning curves in laparoscopic sigmoid resection: eight-year results. Dis Colon Rectum 2003;46:1371-8.

33. Tekkis PP, Senagore AJ, Delaney CP, Fazio VW. Evaluation of the learning curve in laparoscopic colorectal surgery: comparison of right-sided and left-sided resections. Ann Surg 2005;242:83-91.

34. Bennett CL, Stryker SJ, Ferreira MR, Adams J, Beart RW Jr. The learning curve for laparoscopic colorectal surgery. Preliminary results from a prospective analysis of 1194 laparoscopic-assisted colectomies. Arch Surg 1997;132:41-4.

35. Kim YW, Lee HM, Kim NK, Min BS, Lee KY. The learning curve for robot-assisted total mesorectal excision for rectal cancer. Surg Laparosc Endosc Percutan Tech 2012;22:400-5.

36. Bric JD, Lumbard DC, Frelich MJ, Gould JC. Current state of virtual reality simulation in robotic surgery training: a review. Surg Endosc 2016;30:2169-78.

37. Pimentel M, Cabral RD, Costa MM, Neto BS, Cavazzola LT. Does previous laparoscopic experience influence basic robotic surgical skills? J Surg Educ 2018;75:1075-81.

38. Rottoli M, Bona S, Rosati R, Elmore U, Bianchi PP, Spinelli A, et al. Laparoscopic rectal resection for cancer: effects of conversion on short-term outcome and survival. Ann Surg Oncol 2009;16:127986.

39. Baik SH, Kwon HY, Kim JS, Hur H, Sohn SK, Cho CH, et al. Robotic versus laparoscopic low anterior resection of rectal cancer: short-term outcome of a prospective comparative study. Ann Surg Oncol 2009;16:1480-7.

40. Trastulli S, Farinella E, Cirocchi R, Cavaliere D, Avenia N, Sciannameo F, et al. Robotic resection compared with laparoscopic rectal resection for cancer: systematic review and meta-analysis of short-term outcome. Colorectal Dis 2012;14:e134-56.

41. Kim MJ, Park SC, Park JW, Chang HJ, Kim DY, Nam BH, et al. Robot-assisted versus laparoscopic surgery for rectal cancer: a phase II open label prospective randomized controlled trial. Ann Surg 2018;267:243-51.

42. Kim JY, Kim NK, Lee KY, Hur H, Min BS, Kim JH. A comparative study of voiding and sexual function after total mesorectal excision with autonomic nerve preservation for rectal cancer: laparoscopic versus robotic surgery. Ann Surg Oncol 2012;19:2485-93.

43. Park SY, Choi GS, Park JS, Kim HJ, Ryuk JP, Yun SH. Urinary and erectile function in men after total mesorectal excision by laparoscopic or robot-assisted methods for the treatment of rectal cancer: a case-matched comparison. World J Surg 2014;38:1834-42.

44. Langer D, Tučková I, Kalvach J, Ryska M. Can robotic rectal cancer surgery improve quality of total mesorectal excision? Rozhl Chir 2017;96:69-74.

45. Pollack J, Holm T, Cedermark B, Altman D, Holmström B, Glimelius $\mathrm{B}$, et al. Late adverse effects of short-course preoperative radiotherapy in rectal cancer. Br J Surg 2006;93:1519-25. 
46. Kauff DW, Lang H, Kneist W. Risk factor analysis for newly developed urogenital dysfunction after total mesorectal excision and impact of pelvic intraoperative neuromonitoring- a prospective 2-year follow-up study. J Gastrointest Surg 2017;21:1038-47.

47. Duran E, Tanriseven M, Ersoz N, Oztas M, Ozerhan IH, Kilbas Z, et al. Urinary and sexual dysfunction rates and risk factors following rectal cancer surgery. Int J Colorectal Dis 2015;30:1547-55.

48. Eveno C, Lamblin A, Mariette C, Pocard M. Sexual and urinary dysfunction after proctectomy for rectal cancer. J Visc Surg 2010; 147:e21-30.

49. Maurer CA. Urinary and sexual function after total mesorectal excision. Recent Results Cancer Res 2005;165:196-204.

50. Morino M, Parini U, Allaix ME, Monasterolo G, Brachet Contul R, Garrone C. Male sexual and urinary function after laparoscopic total mesorectal excision. Surg Endosc 2009;23:1233-40.

51. Moszkowicz D, Alsaid B, Bessede T, Penna C, Nordlinger B, Benoit $\mathrm{G}$, et al. Where does pelvic nerve injury occur during rectal surgery for cancer? Colorectal Dis 2011;13:1326-34.

52. Wallner C, Lange MM, Bonsing BA, Maas CP, Wallace CN, Dabhoiwala NF, et al. Causes of fecal and urinary incontinence after total mesorectal excision for rectal cancer based on cadaveric surgery: a study from the Cooperative Clinical Investigators of the Dutch total mesorectal excision trial. J Clin Oncol 2008;26:446672.

53. Akyol AM, McGregor JR, Galloway DJ, Murray GD, George WD. Anastomotic leaks in colorectal cancer surgery: a risk factor for recurrence? Int J Colorectal Dis 1991;6:179-83.

54. Law WI, Chu KW, Ho JW, Chan CW. Risk factors for anastomotic leakage after low anterior resection with total mesorectal excision. Am J Surg 2000;179:92-6.

55. Branagan G, Finnis D; Wessex Colorectal Cancer Audit Working Group. Prognosis after anastomotic leakage in colorectal surgery. Dis Colon Rectum 2005;48:1021-6.

56. Peeters KC, Tollenaar RA, Marijnen CA, Klein Kranenbarg E, Steup WH, Wiggers T, et al. Risk factors for anastomotic failure after total mesorectal excision of rectal cancer. Br J Surg 2005;92:211-6.

57. Lee WS, Yun SH, Roh YN, Yun HR, Lee WY, Cho YB, et al. Risk factors and clinical outcome for anastomotic leakage after total mesorectal excision for rectal cancer. World J Surg 2008;32:1124-9.

58. Lin JK, Yueh TC, Chang SC, Lin CC, Lan YT, Wang HS, et al. The influence of fecal diversion and anastomotic leakage on survival after resection of rectal cancer. J Gastrointest Surg 2011;15:2251-61.

59. Evans C, Boden R, Daniels IR, Kumar D. Risk factors for anastomotic failure after total mesorectal excision of rectal cancer $(\mathrm{Br} J$ Surg 2005; 92: 211-216). Br J Surg 2005;92:783.

60. Akiyoshi T, Kuroyanagi H, Oya M, Konishi T, Fukuda M, Fujimoto Y, et al. Factors affecting the difficulty of laparoscopic total mesorectal excision with double stapling technique anastomosis for low rectal cancer. Surgery 2009;146:483-9.

61. Ito M, Sugito M, Kobayashi A, Nishizawa Y, Tsunoda Y, Saito N. Relationship between multiple numbers of stapler firings during rectal division and anastomotic leakage after laparoscopic rectal resection. Int J Colorectal Dis 2008;23:703-7.

62. Kim JS, Cho SY, Min BS, Kim NK. Risk factors for anastomotic leakage after laparoscopic intracorporeal colorectal anastomosis with a double stapling technique. J Am Coll Surg 2009;209:694701.

63. Rahbari NN, Weitz J, Hohenberger W, Heald RJ, Moran B, Ulrich A, et al. Definition and grading of anastomotic leakage following anterior resection of the rectum: a proposal by the International Study Group of Rectal Cancer. Surgery 2010;147:339-51.

64. Huh JW, Kim HR, Kim YJ. Anastomotic leakage after laparoscopic resection of rectal cancer: the impact of fibrin glue. Am J Surg 2010;199:435-41.

65. Bertelsen CA, Andreasen AH, Jørgensen T, Harling H; Danish Colorectal Cancer Group. Anastomotic leakage after anterior resection for rectal cancer: risk factors. Colorectal Dis 2010;12:3743.

66. Kim CW, Baek SJ, Hur H, Min BS, Baik SH, Kim NK. Anastomotic leakage after low anterior resection for rectal cancer is different between minimally invasive surgery and open surgery. Ann Surg 2016;263:130-7.

67. Jafari MD, Lee KH, Halabi WJ, Mills SD, Carmichael JC, Stamos $\mathrm{MJ}$, et al. The use of indocyanine green fluorescence to assess anastomotic perfusion during robotic assisted laparoscopic rectal surgery. Surg Endosc 2013;27:3003-8.

68. Tejedor P, Sagias F, Nock D, Flashman K, Naqvi S, Kandala NL, et al. Advantages of using a robotic stapler in rectal cancer surgery. J Robot Surg 2020;14:365-70.

69. Park IJ, Kim JC. Adequate length of the distal resection margin in rectal cancer: from the oncological point of view. J Gastrointest Surg 2010;14:1331-7.

70. Pollett WG, Nicholls RJ. The relationship between the extent of distal clearance and survival and local recurrence rates after curative anterior resection for carcinoma of the rectum. Ann Surg 1983;198:159-63.

71. Baek JH, McKenzie S, Garcia-Aguilar J, Pigazzi A. Oncologic outcomes of robotic-assisted total mesorectal excision for the treatment of rectal cancer. Ann Surg 2010;251:882-6.

72. Baik SH, Kim NK, Lim DR, Hur H, Min BS, Lee KY. Oncologic outcomes and perioperative clinicopathologic results after robotassisted tumor-specific mesorectal excision for rectal cancer. Ann Surg Oncol 2013;20:2625-32.

73. Kim JC, Lee JL, Alotaibi AM, Yoon YS, Kim CW, Park IJ. Robotassisted intersphincteric resection facilitates an efficient sphincter-saving in patients with low rectal cancer. Int J Colorectal Dis 2017;32:1137-45.

74. Lee KY, Shin JK, Park YA, Yun SH, Huh JW, Cho YB, et al. Transanal endoscopic and transabdominal robotic total mesorectal excision for mid-to-low rectal cancer: comparison of short-term postoperative and oncologic outcomes by using a case-matched analysis. Ann Coloproctol 2018;34:29-35.

75. Sammour T, Malakorn S, Bednarski BK, Kaur H, Shin US, Messick C, et al. Oncological outcomes after robotic proctectomy for rectal can- 
cer: analysis of a prospective database. Ann Surg 2018;267:521-6.

76. Pai A, Marecik SJ, Park JJ, Melich G, Sulo S, Prasad LM. Oncologic and clinicopathologic outcomes of robot-assisted total mesorectal excision for rectal cancer. Dis Colon Rectum 2015;58:659-67.

77. Yoo BE, Cho JS, Shin JW, Lee DW, Kwak JM, Kim J, et al. Robotic versus laparoscopic intersphincteric resection for low rectal cancer: comparison of the operative, oncological, and functional outcomes. Ann Surg Oncol 2015;22:1219-25.

78. Feroci F, Vannucchi A, Bianchi PP, Cantafio S, Garzi A, Formisano $\mathrm{G}$, et al. Total mesorectal excision for mid and low rectal cancer: laparoscopic vs robotic surgery. World J Gastroenterol 2016;22: 3602-10.

79. Lim DR, Bae SU, Hur H, Min BS, Baik SH, Lee KY, et al. Longterm oncological outcomes of robotic versus laparoscopic total mesorectal excision of mid-low rectal cancer following neoadjuvant chemoradiation therapy. Surg Endosc 2017;31:1728-37.

80. Law WL, Foo DC. Comparison of short-term and oncologic outcomes of robotic and laparoscopic resection for mid- and distal rectal cancer. Surg Endosc 2017;31:2798-807.

81. Kim JC, Lee JL, Bong JW, Seo JH, Kim CW, Park SH, et al. Oncological and anorectal functional outcomes of robot-assisted intersphincteric resection in lower rectal cancer, particularly the extent of sphincter resection and sphincter saving. Surg Endosc 2020; 34:2082-94.

82. Asoglu O, Tokmak H, Bakir B, Aliyev V, Saglam S, Iscan Y, et al. Robotic versus laparoscopic sphincter-saving total mesorectal excision for mid or low rectal cancer in male patients after neoadjuvant chemoradiation therapy: comparison of long-term outcomes. J Robot Surg 2020;14:393-9.

83. Allemann P, Duvoisin C, Di Mare L, Hübner M, Demartines N, Hahnloser D. Robotic-assisted surgery improves the quality of total mesorectal excision for rectal cancer compared to laparoscopy: results of a case-controlled analysis. World J Surg 2016;40:1010-6.

84. Kim YS, Kim MJ, Park SC, Sohn DK, Kim DY, Chang HJ, et al. Robotic versus laparoscopic surgery for rectal cancer after preoperative chemoradiotherapy: case-matched study of short-term outcomes. Cancer Res Treat 2016;48:225-31.
85. Barnajian M, Pettet D 3rd, Kazi E, Foppa C, Bergamaschi R. Quality of total mesorectal excision and depth of circumferential resection margin in rectal cancer: a matched comparison of the first 20 robotic cases. Colorectal Dis 2014;16:603-9.

86. Kim JC, Yu CS, Lim SB, Park IJ, Kim CW, Yoon YS. Comparative analysis focusing on surgical and early oncological outcomes of open, laparoscopy-assisted, and robot-assisted approaches in rectal cancer patients. Int J Colorectal Dis 2016;31:1179-87.

87. Marks G, Mohiuddin M, Rakinic J. New hope and promise for sphincter preservation in the management of cancer of the rectum. Semin Oncol 1991;18:388-98.

88. Buess G, Theiss R, Günther M, Hutterer F, Pichlmaier H. Endoscopic surgery in the rectum. Endoscopy 1985;17:31-5.

89. Rimonda R, Arezzo A, Arolfo S, Salvai A, Morino M. Transanal minimally invasive surgery (TAMIS) with SILS ${ }^{\mathrm{TM}}$ port versus transanal endoscopic microsurgery (TEM): a comparative experimental study. Surg Endosc 2013;27:3762-8.

90. Atallah S, Albert M, DeBeche-Adams T, Nassif G, Polavarapu H, Larach S. Transanal minimally invasive surgery for total mesorectal excision (TAMIS-TME): a stepwise description of the surgical technique with video demonstration. Tech Coloproctol 2013;17: 321-5.

91. Schiemer JF, Zimniak L, Grimminger P, Lang H, Kneist W. Robot-guided neuromapping during nerve-sparing taTME for low rectal cancer. Int J Colorectal Dis 2018;33:1803-5.

92. Schiemer JF, Zimniak L, Hadzijusufovic E, Lang H, Kneist W. Novel multi-image view for neuromapping meets the needs of the robotic surgeon. Tech Coloproctol 2018;22:445-8.

93. Atallah S, Parra-Davila E, Melani AG, Romagnolo LG, Larach SW, Marescaux J. Robotic-assisted stereotactic real-time navigation: initial clinical experience and feasibility for rectal cancer surgery. Tech Coloproctol 2019;23:53-63.

94. Brodie A, Vasdev N. The future of robotic surgery. Ann R Coll Surg Engl 2018;100(Suppl 7):4-13.

95. Hamet P, Tremblay J. Artificial intelligence in medicine. Metabolism 2017;69S:S36-40. 